\title{
Thirty Years of Italian-Canadian Writing and the AICW
}

\section{Jim Zucchero}

King's University College, Western University

\begin{abstract}
This essay offers an analysis of the past 30 years of activity in the Italian-Canadian literary community and examines the role of the AICW (Association of Italian-Canadian Writers) in supporting, disseminating and analyzing that literary production. It profiles the work of three important figures (Pivato, D' Alfonso, Di Cicco) and notes their contributions in establishing this literary ground. It also asserts that women have played an essential role, both in their literary contributions, and in organizational capacities (editing anthologies and proceedings, organizing and promoting literary events and conferences). The essay considers practical issues (developments in technology), challenges, and the vital relationship between creative works and literary criticism in this body of writing.
\end{abstract}

Keywords: Italian-Canadian literature, Italian-Canadian criticism, AICW, multicultural writing

In what way and under what conditions will Italian-Canadian writing survive and develop in Canada?... It is my view that this literature will survive and flourish, whether it is part of the literary mainstream or not. There is a spirit behind this literature that is far greater than art grants or book sales. Maybe it is the spirit of our dead immigrant parents and grandparents. (Joseph Pivato, "Nothing Left to Say: Italian-Canadian Writers" in Writers in Transition 1990, p. 35).

In his essay "Nothing Left to Say: Italian-Canadian Writers," published following the first conference of Italian Canadian writers in 1986, Joseph Pivato commented that his academic colleagues at that time were sceptical that critical analysis of Italian Canadian writing could be treated as a legitimate scholarly pursuit. Pivato defended this exercise and set out a number of useful considerations for himself and others in investigating what he claimed to be a substantial and distinctive literary corpus. In the 30 years since then, his assertion has been largely validated: Italian-Canadian writing has indeed survived and expanded. The extent to which it has "flourished" is open to debate. Clearly, a substantive, diverse body of creative work has been generated; that writing has, in turn, stimulated critical analysis that engages some unique perspectives and issues. The Association of Italian Canadian Writers (AICW) has been central to the development of these writers by stimulating and promoting literary production, and by providing a needed forum for the critical reception of their work.

This article offers a perspective on the developments of the past ITALIAN CANADIANA， Vol. XXXIV, (2020), 15-25 
30years, and sets out some questions for moving forward: First, what has the AICW accomplished since it was founded in 1986, and how? Second: What has the impact of this been? What effects and responses have been generated? What are the key issues and challenges; successes and complaints? How has the terrain for writing, publishing, and criticizing this work changed over the past 30 years? Third: What lies ahead? What are the future prospects for Italian-Canadian writing and this association of writers? What will the critical issues be in the next 30 years? Finally: why does this matter? Or does it matter-that literature and criticism in general, and Italian-Canadian writing in particular, should survive and flourish. I think it matters a great deal and I will explain why.

I will begin with several broad assertions: I would suggest that three key ingredients were crucial to the development of the AICW and Italian-Canadian writing in the early years (from 1986 to about 2000). Those critical ingredients were provided in no small measure by three figures, namely: Joseph Pivato, Antonio D'Alfonso, and Pier Giorgio Di Cicco. ${ }^{1}$ Each one of them contributed different talents that, together, nurtured the growth of the organization and Italian-Canadian writing in its crucial infancy. In the latter 15 years, several significant shifts have occurred. Specifically: 1 . The group of active writers has expanded considerably, and women writers have taken a leading role in guiding the work of the Association and producing much of the best writing. 2. Both the range and calibre of the writing have developed in positive ways. Writing about the immigrant experience is no longer the primary focus of this writing; now, it embraces a much more diverse range of topics and experiences and treats them in more complex ways. 3 . The conditions for Italian-Canadian writing have changed, but writing and publishing continue to pose significant challenges. Italian-Canadians have gained ground in terms of social status; many in this literary community now write from positions of privilege. Still, it is not easy. Most writers are also teachers, social workers, lawyers, professors, editors, journalists, urban planners, illustrators, not to mention wives, mothers, and nonnas-still, they make time to write. 4. Obviously, developments in technology and communication have fundamentally changed the mechanics of writing, publishing, and criticism. This topic could sustain a separate essay and merits a full examination separately. ${ }^{2}$ Finally, I would also assert that the relationship between creative and critical

1 The importance of the three figures, Pivato, D'Alfonso and Di Cicco, in the early development of Italian Canadian writing is also commented on in the "Introduction" by Giulia De Gasperi and Licia Canton in Writing Cultural Difference (14). Their contributions are examined in some detail in the present essay.

2 The subject of how technological change is affecting writing, publishing and criticism is a complex matter with far-reaching implications. Recent developments in technology and communication have deeply affected almost every aspect of these activities, from the economics of publishing to the mechanics of printing books. For example, vast amounts of information can now be 
writing is central to understanding Italian-Canadian writing and provides valuable insights into its development and distinctiveness. Specifically, many of the writers and the publications generated are a hybrid of creative and critical impulses, sometimes integrated and sometimes existing as separate entities. This point merits close attention, and I will return to it later.

Evidence of this hybridity - the reciprocity between creative and critical threads, can be found in the work of the three seminal figures I have identified as being vital to the early success of both the AICW and Italian-Canadian writing. Brief profiles of these three key figures, to highlight aspects of their individual character and production, will demonstrate how each has contributed to the overall development of this organization and the work it undertook. In brief, it required much hard work, a renegade spirit, and a mystical vision for Italian-Canadian writing to arrive where it is today.

Joseph Pivato has been widely recognized as a founding father of Italian-Canadian writing, and justly so. In 1986, Pivato was instrumental in the creation of the AICW and became its first president. Steady, reliable, and tireless, he has embodied the kind of work ethic and diligence that every successful organization needs. Francesco Loriggio asserted that cataloguing was the first task in establishing the presence of Italian-Canadian writing; then, "the more embarrassing and inconvenient task of criticism," (pp. 75-76) could begin. ${ }^{3}$ Pivato has undertaken both of those tasks and has pursued them relentlessly for nearly 40 years. Born near Venice, Italy, Pivato moved to Canada as a young child.

accessed instantaneously, from virtually anywhere with access to the internet, often at little or no cost. Entire books and even complete libraries are now portable in electronic formats. The effect of this is underscored if we consider that 30 years ago (when the AICW was founded) there was no internet, no email, no Google or Wikipedia. Joseph Pivato wrote about submitting his poems for Di Cicco's Roman Candles anthology through the mail (i.e. Canada Post). Now, the executive of the AICW holds 'virtual meetings' by Skype and receives transcripts as e-mail attachments. These technological developments have been enormously helpful. And yet, there may also be a downside and unintended adverse consequences to these trends. Research demonstrates that increasing attachment to electronic devices produces a range of changes to behaviour and even brain function: for example, people's attention spans are becoming shorter. We are adrift in a virtual sea of information, so gaining and holding attention for, say, a new book becomes challenging in new ways. Some critics argue that visual images have eclipsed words in digital culture. Will the novel of several hundred pages still be read by the end of the 21st century? Will the pleasure of reflecting on a favourite poem be replaced by a microchip implanted to produce similar feelings of contentment? These may seem like unlikely scenarios, but who guessed a mere thirty years ago that our current communications would look like they do today? And the pace of these changes is only accelerating! Sarina Ricci examines some of these issues in her article "The Fate of Reading in a Multimedia Age."

${ }^{3}$ Loriggio's essay remains a rich, provocative piece for approaching the critical issues that prevail. 
He excelled at school, completed his PhD at the University of Alberta (1977), and eventually took a position teaching at Athabasca University. From there he began to engage and confront the academy as one of their own. Pivato was among the first to recognize that the writing produced by Italians in Canada is distinctive and merits close attention. He has made it his life's work to promote and support that assertion.

His most noteworthy contribution may be his seminal and pioneering writing about minority literatures in Canada and internationally. His early collections of critical essays-Contrasts: Comparative Essays on Italian-Canadian Writing (1985) and Echo: Essays on Other Literatures (1994) were among the first substantive critical writing to examine the work of Italian-Canadian writers like F.G. Paci, Mary Di Michele, Caterina Edwards, Pier Giorgio Di Cicco, and others writing from the so-called "margins." Since then he has edited individual collections of essays on many of these writers.

In 1998, Pivato edited The Anthology of Italian-Canadian Writing, an important text that showcases the work of some 50 writers of Italian heritage. In the introduction, he notes that Italians have been writing about life in what we now call Canada since as far back as 1653 with the writings of F. G. Bressani. He suggests that Italian-Canadian literature began in earnest with Di Cicco's Roman Candles in 1978, an anthology of poems that Pivato calls the first "self-conscious realization about our writing" (13). Some of Pivato's poems were included in that collection. Many of his essays explore what constitutes the distinctiveness of Italian-Canadian writing and how it contributes to broader conversations about multiculturalism in Canada. His work has influenced countless others working in this field (myself included). Pivato remains actively involved in the AICW and his crucial role in establishing the ground for Italian-Canadian writing as we know it can hardly be overstated.

The critical work that Pivato did depended significantly on those early works of Italian-Canadian literature being published. No one was more important to getting that work published than Antonio D'Alfonso. In 1978 he established Guernica Editions. For the next 32 years (until 2010) he published works (about 450 in total) that more mainstream publishers would not embrace, including many works by Italian-Canadian writers. He often edited and translated as well.

D' Alfonso represented a kind of 'renegade' spirit. He was, in some ways, the embodiment of the claim that Pivato was staking: that there is a message in this writing, that it is a different voice, and that it should be heard. Sometimes he came across as irascible, adversarial; but he was OK with that perception. He took chances; he did what had to be done to ensure that good writers saw their works in print, even, or especially if they were not "mainstream." At the same time, D' Alfonso developed his voice as a leading critic of what he calls the "italic" condition. His work takes many forms: poetry, essays, editorials, novels, and films. As a Canadian, born in Montreal to Italian immigrant parents, educated and immersed in a French-Canadian culture, he poses penetrating ques- 
tions about the nature of Italian culture as it exists and is transformed when it migrates outside of Italy. He wrestles with questions of identity and language. D'Alfonso and Pasquale Verdicchio were foils to each other in testing and articulating their ideas about the place of 'italic' writing in North America. In 2010 D' Alfonso left the publishing industry; and he completed his PhD at the University of Toronto in film studies. He now spends most of his time in Toronto and Montreal where he continues to write, teach, translate, and work on various creative projects. D'Alfonso continues to be a strong, provocative voice on important issues in the arts and culture.

If $\mathrm{D}^{\prime}$ Alfonso may be said to symbolize something of the renegade spirit that was required to establish the ground of Italian-Canadian writing, Pier Giorgio Di Cicco is clearly its guiding light, its mystical shaman. Di Cicco's anthology of poetry Roman Candles was a watershed when it was published in 1978; as he noted: "all involved were surprised by the anthology itself. It puts a stop to the aforementioned isolationism." (9) That comment provides a useful insight into Di Cicco's overarching motivation in life; namely, to close the gap, to bring people together, to promote real community and genuine civility as a counterforce to rampant individualism and the pursuit of self-interest.

Like D'Alfonso, Di Cicco has worn many hats: he was the editor of Books in Canada; he has taught, and has published more than 20 volumes of poetry; he was the Poet Laureate of Toronto (from 2005-2009); in the 1990s he took religious orders and was ordained a Catholic priest. Di Cicco's gift is to move seamlessly between the micro and macro. He challenges our notions of citizenship and belonging, civility and creativity... and he is deeply moved by his own Italianità, an Italian aesthetic sensibility that he knows to be a part of his core. So, he asks the big questions: what kind of society do we want? How should we go about creating it? Who is responsible: politicians, individual citizens, civic leaders? Di Cicco challenges us to imagine and then create a world different than the one we know.

In 2007 he published Municipal Mind - Manifestos for the Creative City, a synopsis of his thinking about the "civic aesthetic-a term coined to define building a city by citizenship, civic ethics and urban psychology." (IdeaCity) The reflections in that manifesto resonate with the sentiments expressed in his inspired volumes of poetry from a few years earlier, The Honeymoon Wilderness (2002) and The Dark Time of Angels (2003). The creative and the critical are no strangers to each other in Di Cicco's writing; in fact, to suggest they could exist apart from each other would seem anathema to him.

Apart from his prolific output Di Cicco has had a strong and enduring influence on the development of other writers, including Mary Di Michele and Josie Di Sciascio-Andrews, just two award-winning writers who note that his support and encouragement was critical to their development as writers. (see Fazio 110 and Okun Hill 130) Many others would make a similar claim. Di Cicco's mission is to inspire transformation, both personal and social; to prod us to see 
things anew and to cultivate greater cohesiveness in our relationships and our communities. I see in his writing what Martha Nussbaum praises as the highest and most vital function of the arts, literature, poetry, and philosophy... namely, the promotion of 'global citizenship.' In Duologue: On Culture and Identity by Antonio D'Alfonso and Pasquale Verdicchio (1998), the latter suggested that Italian-Canadian writers have to become "activists"; Di Cicco's writing, his public presence, and his life of service are one prime example of such activism.

\section{The shift: The AICW and Italian-Canadian Writing in the $21^{\text {st }}$ Century}

Antonio D' Alfonso is quoted as saying: "If there is a future for our community it is in the presence of women intellectuals and artists." (quoted in Canton 7 and De Gasperi 41). History may prove D'Alfonso correct on this count. Of course, women participated at the very earliest stages of the AICW coming together; Anna Foschi Ciampolini and Venera Fazio have written about those events. ${ }^{4}$ If we consider the volume and the calibre of Italian-Canadian writing produced in recent years, I would assert that women writers have risen to the forefront of this movement. They have provided leadership in the AICW, organized public reading events, raised the profile of Italian Canadian writing, and produced (arguably) much of the best writing. The publication of Pillars of Lace: The Anthology of Italian-Canadian Women Writers (see De Franceschi) in 1999 was an important milestone on this trajectory. In 2016, Exploring Voice: Italian Canadian Female Writers (see Fazio and De Santis) was released as the latest instalment in this saga. In a novel twist, contributors to this collection were invited to submit creative work and an essay or interview in which they reflect on how and why they write. The complementary pieces engage a wide range of literary styles and convey some of the challenges that these writers have contended with to bring their work to publication. Again, the combination of creative writing with critical essays helps to articulate an important dynamic and underscores the contributions that these writers are making, both within the Italian-Canadian writing community and beyond it.

I find further evidence for the predominance of women writers at present in the announcements I receive about reading events and Salotti. Recent events in Toronto included: "The (Not so) Nice Italian Girls and Friends," a presentation of poetry, prose and comedy by 15 Italian-Canadian women, billed as the "Amazons of the Mediterranean"; "Bloodlines" readings by daughters and fathers to celebrate Italian Heritage Month; and Gianna Patriarca's presentation of short fiction from her latest collection All My Fallen Angelas. ${ }^{5}$

In recent years, members of the supporting chorus have taken

4 See Minni and Foschi Ciampolini; De Gasperi, De Santis and Morgan Di Giovanni.

5 Notice of these events is circulated by e-mail to a list of subscribers and pro- 
leading roles in providing the three key ingredients. The tireless work of organizing events and promoting the circulation of Italian-Canadian writing is now being done by Licia Canton, Venera Fazio, Giulia De Gasperi, Maria Cristina Seccia, Connie McParland, Caroline Morgan di Giovanni, Anna Foschi Ciampolini, and others. The renegade spirit is now being expressed by Michelle Alfano, Terri Favro, Eufemia Fantetti, Gianna Patriarca, Darlene Madott, Giovanna Riccio, and a few male writers like Domenico Capilongo and Frank Giorno. The mystic sensibility and visionary optimism of Pier Giorgio Di Cicco is finding its expression through writers like Isabella Colallillo Katz, Sonia di Placido, Marisa De Franceschi, Venera Fazio, Delia De Santis, Gianna Patriarca, and others.

\section{On the relationship between criticism and creative writing:}

Let me return to the assertion I made earlier: that the relationship between creative and critical writing is essential to understanding the development of Italian-Canadian writing as a whole. Clearly, there is much more creative writing than critical analysis of it. Why, and what resides in this point? The short answer, of course, is that there are many more writers than critics. Should this be a concern? One recurring motif at biennial AICW conferences has been that Italian-Canadian writing is not recognized sufficiently, doesn't get its due, is not appreciated or respected as it ought to be. ${ }^{6}$ Is this true? Why is a critical response to this writing so important?

First, I think it is important to reject as a false binary the notion that creative work and criticism are separate or somehow opposed to each other. They are not; in fact, the reverse is more often true: The best and most insightful criticism is inherently creative work. It examines and explains key features of a work of art in ways we might not have apprehended; it connects the work of art to critical contemporary issues or other works of art; so, it helps us comprehend the creative act or work more fully, and appreciate it more deeply. Conversely, the most engaging creative works always include a strong measure of critical incisive-

moted through popular social media (Facebook and Twitter); this is a graphic illustration of the potential benefits of developments in technology affecting communications. "The (Not so) Nice Italian Girls and Friends" event took place in Toronto on June 22/16; "Bloodlines" happened on June 16/16 in Toronto; and Gianna Patriarca's reading from All My Fallen Angelas occurred on June $23 / 16$ at the Istituto Italiano di Cultura (Toronto).

6 Unpacking this complaint is a complex matter. At its core, the claim might translate as: we still are not viewed as part of 'mainstream' Canadian literature. But how are we to measure this? By book sales? The tone of literary reviews? Social media 'likes'? Inclusion in course curriculum, and syllabi? Literary awards, nominations and writers' prizes? Amount of serious literary analysis generated at academic conferences-and which ones? Some combination of these metrics? Who decides what constitutes the success of a piece of writing? 
ness - about individual characters and their motivations; about families and their complex dynamics; or whole societies, nations, and the human condition.

Here the issue of self-reflexivity arises, and this is a conundrum; it is an awkward truism that the critics of Italian-Canadian writing are mostly Italian-Canadian writers. The balance has improved slightly since the early days, but the problem persists. In the 1980 s and ' 90 s, it was a very small group involved. Often, the same people who were producing creative works were conducting much of the critical analysis. The circle has expanded, but the issue remains, and it's a Catch-22. If we don't do this work who will? However, we are perceived as insiders at best, or cheerleaders at worst, lacking in objectivity. So, does our cultural awareness enhance our perceptions, or contaminate our judgements? Or is it both?

Second: why is criticism important-especially criticism from outside of our group, or is it? Why not just focus on creating good new works of art? Good poems and novels and film scripts... Because the critical analysis is a marker of being taken seriously. By the academy, if our works are included in the curriculum. By the public at large if our works are reviewed in newspapers, magazines and journals, or on websites and through social media. Literary awards have become another important marker of acceptance and esteem, for better or worse. The public profile that arises from criticism creates awareness, curiosity, and demand for what we do; that, in turn, supports the distribution, circulation, and sale of our works. More criticism does not necessarily mean better criticism, but it likely increases the odds that some of it will be good. As Gundula Wilke noted in her 2003 review in Canadian Literature: "If the contributions of these 'ethnic' writers to Canadian literature are ignored by general readers, by teachers and critics, or if they are merely subjected to stereotypical analysis, a major part of our culture in Canada is silenced or misrepresented, and the focus remains limited to the dominant groups" (165). Criticism matters because nothing develops without effective criticism. The reciprocity and tension between creative writing and effective criticism of that work in Italian-Canadian writing have enhanced the development of both.

Finally: why do these things matter-art, literature, ItalianCanadian writing? Italian-Canadian writing contributes uniquely to broader Canadian and global conversations about literature and art that help us to understand the complex world we live in, our lives, and those of others. It does this by constantly circling back in and out of orbit with the concept of migration. ${ }^{7}$ Over the course of the $20^{\text {th }}$ century, Italians departed from Italy in record numbers and transplanted themselves around the world. They journeyed to lands unknown and had to

7 Departures, journeys, destinations, and the impact of migration have been recurring motifs in much Italian-Canadian literature, and at past AICW conferences. These issues remain, for me, at the very centre of Italian-Canadian writing. 
re-invent themselves. As Italians abroad they have had to learn new languages, understand other cultures and adapt to a different milieu. They have made a difference everywhere they settled: in America (including Canada), in Argentina, and Australia. In migrating from their homeland, many Italians came to understand what is essential to them and what they cherish most: the freedom to pursue their goals and embrace their identity. In adjusting to life in foreign places, they also came to appreciate firsthand the difficulties of that experience for every migrant. Writing about that journey has put Italian-Canadian writers in touch with something deep and vital; paradoxically, it is both unique to them in some ways, and universal in others.

Recently it was reported that: "The world's refugee population has soared to an all-time record of 63.5 million [people]... according to the latest report from the UNHCR. But much of the world is increasingly responding with xenophobia, divisive rhetoric, closed borders, and political paralysis." (York). ${ }^{8}$ Migrants have written about the experience of migration since the dawn of time as a means of trying to understand the strangeness that accompanies dislocation. The destination for each writer is different: some write to reconcile a lost or difficult past; some to better understand their Italian heritage and how it affects them. Some write to try to know themselves and their world a little better. All are better for having written. Pier Giorgio Di Cicco has said: "The primal desires of the human spirit are desires for delight and creativity. These desires meet in moments of wonder when people of different nationalities and ideologies share a moment of wonder. Moreover, that wonder spills over and makes for trust, and reciprocity, and mutuality." (IdeaCity)

So, finally, does it matter?- that Italian-Canadian writing should survive, or better still flourish? I think it matters more now than ever because the world is getting smaller day-by-day. Globalization is ubiquitous. Our capacity to accept, embrace and even celebrate this cultural diversity is more critical now than ever before. I firmly believe that the arts-and especially good writing, can play an important role in helping us to manage some of the difficult challenges of pluralism. Martha Nussbaum makes this case eloquently in her 2010 book entitled Not for Profit: Why Democracy Needs the Humanities; she writes: "We live in a world in which people face one another across gulfs of geography, language and nationality...The problems we need to solve-economic, environmental, religious, political-are global in their scope. They have no hope of being solved unless people once distant come together and cooperate in ways they have not before" (79). She talks about "the task of teaching intelligent world citizenship" and emphasizes the role of

8 Ironically, Italians, who were among the greatest number of migrants in the 20th century, are now faced with the most compelling and challenging questions around how to respond humanely and responsibly to the greatest migration in human history: a refugee crisis of stunning proportions that is breaking on Italian shores. 
education, and especially the arts and humanities as they are taught in colleges and universities, in cultivating the understanding needed to address the enormous challenges we face.

The need for compassion, understanding, tolerance and generosity has never been greater. But to cultivate such responses, we must first defuse fear, prejudice, apathy and ignorance. Can writing that deals with the experience of cultural difference, adjustment, assimilation and overcoming barriers contribute to this work? Like Nussbaum, I believe it can. I would assert that Italian-Canadian writing, in its many diverse forms, has much to teach us about the capacity for literature to do some of this work. The writers in this community, the work they have done, and the writing they have produced over the past 30 years, provide an excellent example of what can be accomplished where there is: a willingness to work tirelessly against difficult obstacles; a bit of renegade attitude that says: 'well, we think we can, and we'll do it our way'; and a mystic spirit that refuses to be quelled, and seeks to grow through exposure to the new and the different.

\section{Works Cited}

Canton, Licia. "Italian Canadian Literature: Our Women Our Writers." Italian Canadiana 20 (2006): 5-14.

D'Alfonso, Antonio and Pasquale Verdicchio. Duologue: On Culture and Identity. Toronto: Guernica, 1998.

De Franceschi, Marisa (Ed.). Pillars of Lace: The Anthology of Italian Canadian Women Writers. Toronto: Guernica, 1999.

De Gasperi, Giulia. "The Many Facets of Domestic Life: Licia Canton's Almond Wine and Fertility." In Fazio, Venera, and Delia De Santis (Eds.). Exploring Voice: Italian Canadian Female Writers. Special Issue of Italian Canadiana 30 (2016): 41-46.

De Gasperi, Giulia, Delia De Santis, Caroline Morgan Di Giovanni (eds.). People, Places, Passages. An Anthology of Canadian Writing. Montreal: Longbridge Books, 2018.)

De Gasperi, Giulia, Maria Cristina Seccia, Licia Canton and Michael Mirolla (Eds.). "Introduction". Writing Cultural Difference: Italian-Canadian Creative and Critical Works (pp. 13-21). Toronto: Guernica: 2015.

De Gasperi, Giulia, Maria Cristina Seccia, Licia Canton and Michael Mirolla (Eds.). Writing Cultural Difference: Italian-Canadian Creative and Critical Works. Toronto: Guernica: 2015.

Di Cicco, Pier Giorgio. IdeaCity (2006) (video) web link: http:/ / www.ideacity. ca/speaker/pier-giorgio-di-cicco. Retrieved 22 October 2019.

Municipal Mind-Manifestos for the Creative City. Toronto: Mansfield Press, 2007.

"Preface". In Roman Candles: An Anthology of Poems by Seventeen ItaloCanadian Poets, edited by Pier Giorgio Di Cicco (pp. 9-12). Toronto: Hounslow Press, 1978.

The Honeymoon Wilderness. Toronto: Mansfield Press, 2002.

The Dark Time of Angels. Toronto: Mansfield Press, 2003.

Di Cicco, Pier Giorgio (Ed.). Roman Candles: An Anthology of Poems by Seventeen Italo-Canadian Poets. Toronto: Hounslow Press, 1978.

Fazio, Venera. "Mary Di Michele: Love Imitates." In Fazio, Venera, and Delia De 
Santis (Eds.). Exploring Voice: Italian Canadian Female Writers. Special Issue of Italian Canadiana 30 (2016): 109-114.

Fazio, Venera, and Delia De Santis (Eds.). Exploring Voice: Italian Canadian Female Writers. Italian Canadiana 30 (2016).

Loriggio, Francesco. "Italian-Canadian Writing: Basic Critical Issues," in Writers in Transition: The Proceedings of the First National Conference of ItalianCanadian Writers, edited by C.D. Minni and Anna Foschi Ciampolini. Montreal: Guernica, 1990. Pp. 73-96.

Minni, C. Dino and Anna Foschi Ciampolini (Eds.) Writers in Transition: The Proceedings of the First National Conference of Italian-Canadian Writers. Montreal: Guernica, 1990.

Nussbaum, Martha. Not for Profit: Why Democracy Needs the Humanities. New Jersey: Princeton UP, 2010.

Okun Hill, Debbie. "Josie Di Sciascio-Andrews: Memories in the Sand." In Fazio, Venera, and Delia De Santis (Eds.). Exploring Voice: Italian Canadian Female Writers. Special Issue of Italian Canadiana 30 (2016): 125-131.

Pivato, Joseph. Echo: Essays on Other Literatures. Toronto: Guernica, 1994. . "Nothing Left to Say". In Writers in Transition: The Proceedings of the First National Conference of Italian-Canadian Writers, edited by C.D. Minni and Anna Foschi Ciampolini. Montreal: Guernica, 1990. Pp. 27-41.

Pivato, Joseph (Ed.). Contrasts: Comparative Essays on Italian-Canadian Writing. Montreal: Guernica, 1985.

The Anthology of Italian-Canadian Writing. Toronto: Guernica, 1998.

Ricci, Sabrina. "The Fate of Reading in a Multimedia Age" https: / / lareviewofbooks.org/article/fate-reading-multimedia-age/ 20/11/2016. Retrieved 22 October 2019.

Wilke, Gundula. "Tricultural Landscape: The Anthology of Italian-Canadian Writing/ Pillars of Lace: The Anthology of Italian Canadian Women Writers/ Duologue: On Culture and Identity." Canadian Literature 178 (Autumn 2003): 164-66.

York, Geoffrey. "Poor Countries Bearing Brunt of Record Refugee Population." The Globe and Mail, A1, June 20, 2016. 